\title{
A Control Chart Based on Moving Average Model Functioned for Poisson Distribution
}

\author{
Hira Arooj ${ }^{1}$, Khawar Iqbal Malik ${ }^{2}$ \\ ${ }^{1}$ Department of Mathematics \& Statistics, University of Lahore, Pakistan \\ ${ }^{2}$ Department of Computer Science, Pakistan, University of Lahore, Pakistan
}

\begin{abstract}
A control chart used with MA control chart to track the number of faulty products or faults suggested. When the characteristics of quality of interest obey a Poisson distribution. A specified number of objects are observed at various time intervals in order to observe the number of non-conformities. By measuring ARLs under different sample sizes and parameters by considering ARLs in power, the output of the proposed chart is evaluated. It should be noted The proposed control chart seems to be more reliable than the traditional current control charts in detecting small adjustments in the manufacture process.
\end{abstract}

KEYWORDS: Moving Average, Average run length, Control chart, Poisson distribution

\section{INTRODUCTION}

A product quality is the key factor industry needs to retain its market position. To improve the quality of a product, Walter Shewhart introduced quality control charts used to monitor the performance of product during production [1]. Quality control charts are the graphs that display the process data and are trouble-free for the practitioner to utilize and infer. These control charts assist us to make sure that during manufacturing, the process operates properly and producing such products that meets the requirements of the customer. During the production process, many processes parade variability that can be divided into two: sorts: 'natural' otherwise 'unnatural'. Natural variation is considered as systematic variation which is a regular part of the process and it is due to some common causes. Moreover the in process observations also assume natural variation which shows deviation from the regular process. Unnatural variation is also known as non-systematic variation which occurs due to some assignable cause or special cause includes failure of the equipment, time management, change in population or staff, rate of disease or patient's etc [2]. [3]. A process is said to be statistical in control process if it exhibit natural variation remains unchanged and stable with respect to time. A process is said to be statistical out of control process if it possess unnatural variation and the process is not stable with respect to time. Control charts contain three horizontal lines called, the middleline, upper limit of control and lower limit of control (Benneyan, 1998). These three limits define central trend and natural variation of the procedure. The middleline shows simple average (sums mean) or probable value of the plot observations and almost half of the values will fall within each side [4]. The upper and lower control limits are set according to the centerline by adding and subtracting $3 \sigma$ (standard deviation) of the plotted points. A process is statistically in control if $99.73 \%$ of all the points or values lie within the control limits over an interval of time. The most important thing is that make sure that between the limits there is no random variation like trend, cycle etc, if there is any random pattern is observed or any point fall outside the limit, indicates that the course of action is going out of control and some measurements be supposed to be taken to reduce the number of non-conformities [5]. The control chart is considered as a basic tool of quality control and often used for time series data; they can be used to compare the different samples collected at same interval of time [6]. However it is more important to choose the correct type of organize chart. Control charts offer us more information about process presentation, variation occurred in data and changes in process.

Control charts can be classified into two major sorts, variable control charts and attribute control charts. Variable control charts are applicable only while the quality characteristic of interest is measurable and can be expressed in terms of numbers, such as length, weight, volume, temperature and time. Variable control charts include X bar R chart, X bar s chart and moving range charts. Attribute control charts are used as quality a attribute of interest not measured numerically and classified in terms of discrete data (Pass or fail, yes or no, defective or non-defective etc). 
ISSN: 2581-8341

Volume 03 Issue 10 October 2020

DOI: 10.47191/ijcsrr/V3-i10-02, Impact Factor: 6.595

IJCSRR@ 2020

WwW.ijcsrr.org

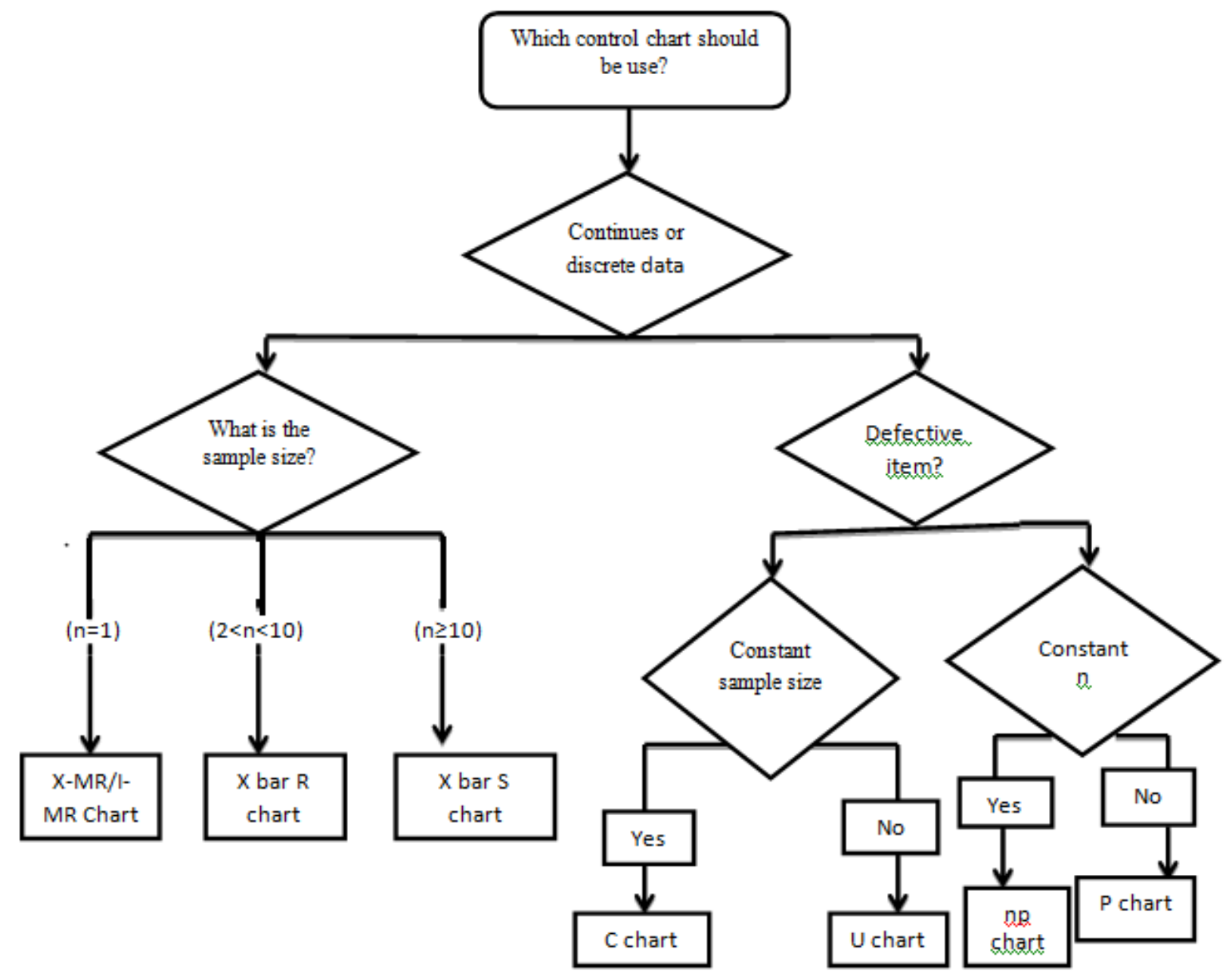

Figure 1: Classification of control chart

\section{MOVING AVERAGE CONTROL CHART}

Moving average control chart is a un weighted control chart and is used to detect small shift in process mean during production process. This control chart is basically used to monitor the stability of production process over time and when we identify any instability during production it indicates that some corrective measures should be taken to reduce the number of defects [7]. It uses the mean of current data and previous mean to construct each moving average and based on the sample taken a given time (time may be in hours, days, months or years etc.) [8]. It based on the specific target value and a consistent estimate of standard deviation so that's why moving average control is considered as better chart when the production process established. They can detect shift from 0.5 to 2 sigma much faster than traditional control chart.

Providing a new control chart for non normal distributions is always valuable for statisticians. Thus, the aim of this paper is to construct a MA controlc chart for the Poisson distribution. The fact that the Poisson distribution generalizes existing commonly used distributions and introduces new control chart [9].

Further, we demonstrate that the proposed chart provides a significant improvement in the world of quality control.In addition, we also investigate the in control and out of control sample points.

The perofrmance of the proposed control chart is evaluated in comparison with the S and EWMA. In the end the conclusion and the furthur suggections have been given. 


\section{International Journal of Current Science Research and Review}

ISSN: 2581-8341

Volume 03 Issue 10 October 2020

DOI: 10.47191/ijcsrr/V3-i10-02, Impact Factor: 6.595

IJCSRR@ 2020

www.ijcsrr.org

\section{POISSON DISTRIBUTION}

Poisson distribution belongs to discrete family of distribution and is discovered by French mathematician Simeon Denis Poisson in 1837. It states the probability of rare events occurred in a fixed interval of time and each event is independent of the time. All the events are independents means that the probability of one event does not affect the probability of other events. The rate at which the events occurred should be constant.

Generally the probability mass function of Poisson distribution is

$$
p(X ; x)=\frac{e^{-\mu} \mu^{x}}{x !}
$$

Where $\mu$ the average number of events in time interval is, also called rate parameter and $e$ is the exponent (Euler's number $=2.7182)$ and $x$ takes values as $0,1,2,3 \ldots$

The above equation can be modified instead of average number of events $\mu$, we are given a time rate $r$ for an event to happen that is $\mu=r t$, so the above equation is written as

This is the probability of success, the probability of failure is

$$
p(\mathrm{x} \text { events in time interval } \mathrm{t})=\frac{e^{-r t} r t^{x}}{x !}
$$

$$
p_{o}=1-\frac{e^{-r t} r t^{x}}{x !}
$$

\section{MOVING AVERAGE STATISTICS}

The moving average statistics of mass " $w$ " at time " $t$ " could be calculated as

$$
M A_{i}=\frac{D_{i}+D_{i-1}+\cdots,+D_{i-w+1}}{w}
$$

Where $D_{i}$ is the number of defects and it is more important that $D_{i}$ follows binomial distribution and $w$ is the size of the moving average.

Mean

And the variance is given as

$$
E\left(M A_{i}\right)=E\left(D_{i}\right)=n p_{o}
$$

$$
\begin{gathered}
\operatorname{Var}\left(M A_{i}\right)=\frac{1}{w^{2}} \sum_{j}^{i} \operatorname{Var}\left(D_{i}\right) \\
=\frac{1}{w^{2}} \sum_{i-w+1}^{i} n p_{o}\left(1-\mathrm{n} p_{o}\right) \\
=\frac{n p_{o}\left(1-n p_{o}\right)}{w}
\end{gathered}
$$

The estimation of the $E\left(D_{i}\right)$ and $\operatorname{Var}\left(D_{i}\right)$ requires the known distribution of all $\left(D_{i}\right)^{\prime} s$.

\section{1- Control Limits:}

The control limits are the specific natural limits for production process and are drawn horizontally during a process, usually takes \pm 3 sigma (standard deviation). The control limits for moving average chart is declared as;

$\mathrm{LCL}=n p_{o}-k \frac{\sqrt{n p_{o}\left(1-n p_{o}\right)}}{w}$

$\mathrm{UCL}=n p_{o}+k \frac{\sqrt{n p_{o}\left(1-n p_{o}\right)}}{w}$

These limits will declare that the process is statistically in control if $\mathrm{MA}_{\mathrm{i}}>\mathrm{UCL}$ and out of control if $\mathrm{MA} \mathrm{A}_{\mathrm{i}}<\mathrm{LCL}$.

\section{COMPARISON OF ARLS, PROPOSED MA, S \& EWMA CONTROL CHART}

This section describes the performance of control chart by calculating average run length and moving averages under different sample sizes such as 100, 150, 200 and 250 and different values of moving average statistics such as 3, 5, 7 and 9. Average run length is considered as a best approach for evaluating the performance of any control chart. 
International Journal of Current Science Research and Review

ISSN: 2581-8341

Volume 03 Issue 10 October 2020

DOI: 10.47191/ijcsrr/V3-i10-02, Impact Factor: 6.595

IJCSRR@ 2020

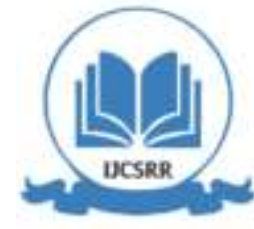

WWW.ijcsrr.org

Table 1: ARLs when $w=3$

\begin{tabular}{|c|c|c|c|c|c|c|c|c|c|c|c|c|}
\hline & \multicolumn{3}{|l|}{$n=100$} & \multicolumn{3}{|l|}{$n=150$} & \multicolumn{3}{|l|}{$n=200$} & \multicolumn{3}{|l|}{$n=250$} \\
\hline & \multirow{2}{*}{ 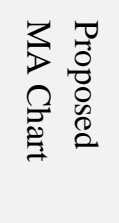 } & \multicolumn{2}{|c|}{ Existing chart } & \multirow{2}{*}{ 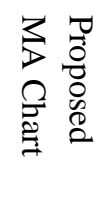 } & \multicolumn{2}{|c|}{ Existing Chart } & \multirow{2}{*}{ 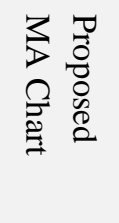 } & \multicolumn{2}{|c|}{ Existing Chart } & \multirow{2}{*}{ 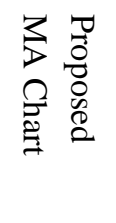 } & \multicolumn{2}{|c|}{ Existing Chart } \\
\hline & & $\stackrel{\sim}{\Omega}$ & 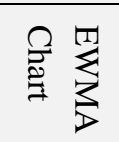 & & $\stackrel{\sim}{2}$ & $\stackrel{\Omega}{\overparen{T}}$ & & 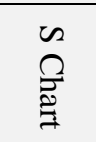 & 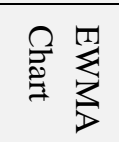 & & 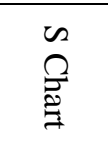 & 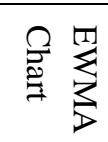 \\
\hline$\delta$ & \multicolumn{12}{|l|}{ ARLs } \\
\hline 1 & 370.49 & 326.7 & 375.29 & 365 & 375.49 & 329.8 & 374.75 & 356.7 & 364.29 & 370.05 & 343.6 & 371.75 \\
\hline 0.99 & 322 & 256.8 & 303.53 & 275 & 333.73 & 267.4 & 274.48 & 243.5 & 298.82 & 299.57 & 212.8 & 276.49 \\
\hline 0.95 & 244.57 & 226.6 & 139.41 & 140 & 208.64 & 243.8 & 198.75 & 198.2 & 219.79 & 110.98 & 108.5 & 192.74 \\
\hline 0.92 & 116.45 & 208.9 & 81.28 & 93 & 146.22 & 149.5 & 147.26 & 96.7 & 165.35 & 57.37 & 54.3 & 145.25 \\
\hline 0.9 & 67 & 181.5 & 60.09 & 47.25 & 115.13 & 87.12 & 93.93 & 81.4 & 145.51 & 37.86 & 42.08 & 54.92 \\
\hline 0.85 & 58.89 & 44.8 & 28.08 & 28.92 & 65.41 & 56.43 & 74.44 & 69.7 & 120.65 & 15.99 & 14.7 & 39.92 \\
\hline 0.8 & 17.88 & 28.7 & 16.25 & 15.2 & 38.47 & 32.6 & 68.35 & 52.5 & 111.51 & 8.21 & 9.67 & 25.2 \\
\hline 0.7 & 8.49 & 14.67 & 7.41 & 9.69 & 14.37 & 17.8 & 45.98 & 41.8 & 55.93 & 3.77 & 5.32 & 17.76 \\
\hline 0.6 & 3.95 & 7.34 & 5.34 & 7.67 & 6.28 & 8.43 & 35.09 & 24.6 & 43.09 & 3.06 & 3.11 & 15.51 \\
\hline 0.5 & 3 & 5.12 & 3.2 & 7 & 3.12 & 6.23 & 21 & 18.1 & 9.87 & 3 & 3.01 & 7.09 \\
\hline
\end{tabular}
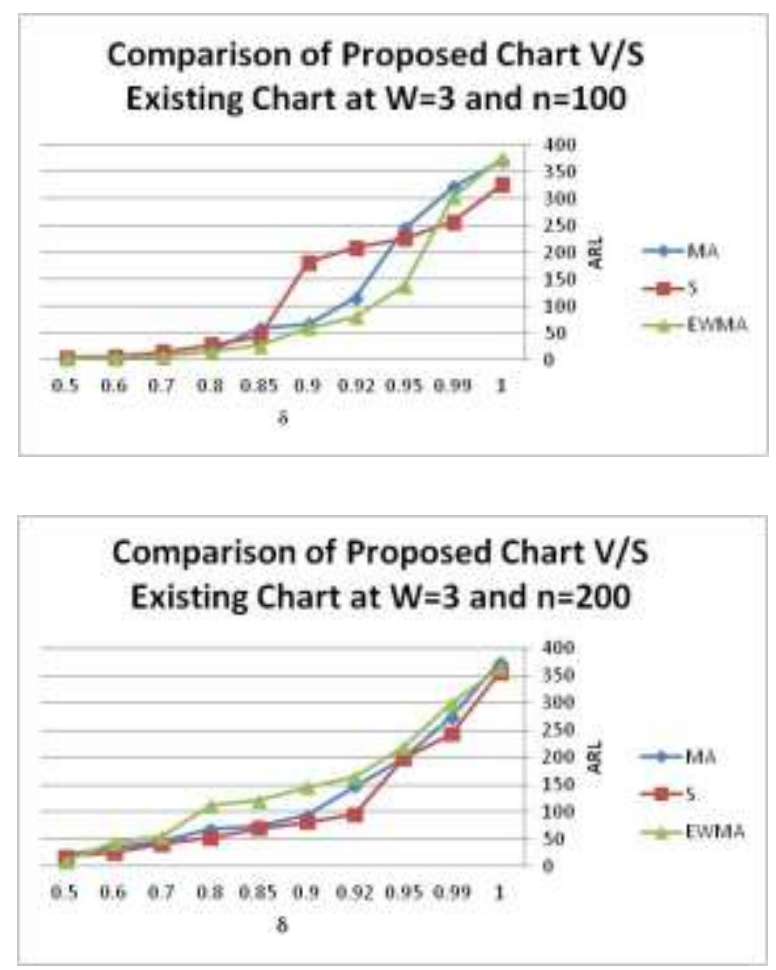
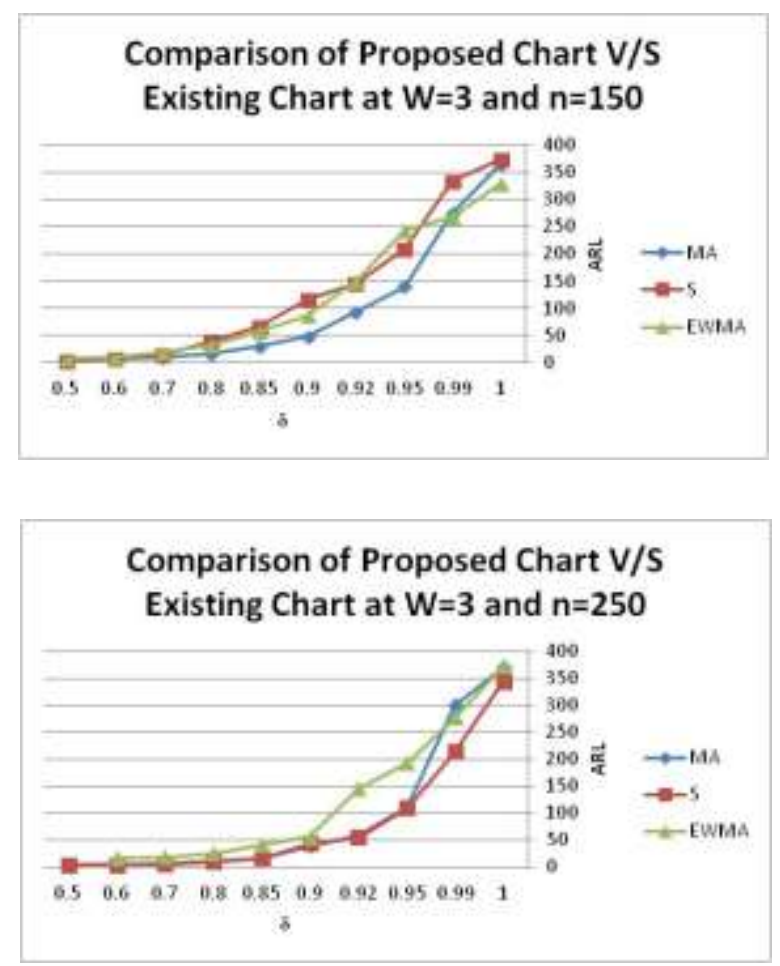

Figure 2: ARL Comparison at $\mathrm{W}=3$ and $n=100,150,200,250$

On comparison we observe when $w=3, n=100$ in proposed MA control chart, then all the points fall within the control limit and the process is in control. When $\mathrm{n}=150,200$ is used under $\mathrm{w}=3$ then all the points also fall within the limit and there is no indic ation of the false alarm. When $w=3, n=250$ there are 1 points that are out of control may be due to some assignable cause. 
International Journal of Current Science Research and Review

ISSN: 2581-8341

Volume 03 Issue 10 October 2020

DOI: 10.47191/ijcsrr/V3-i10-02, Impact Factor: 6.595

IJCSRR@ 2020

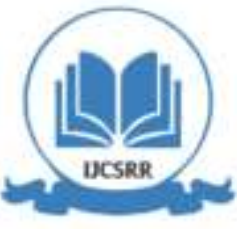

WWW.ijcsrr.org

Table 2: ARLs when $w=5$

\begin{tabular}{|c|c|c|c|c|c|c|c|c|c|c|c|c|}
\hline & \multicolumn{3}{|l|}{$n=100$} & \multicolumn{3}{|l|}{$n=150$} & \multicolumn{3}{|l|}{$\mathrm{n}=\mathbf{2 0 0}$} & \multicolumn{3}{|l|}{$n=250$} \\
\hline & \multirow{2}{*}{ 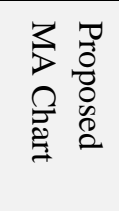 } & \multicolumn{2}{|c|}{ Existing chart } & \multirow{2}{*}{ 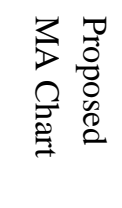 } & \multicolumn{2}{|c|}{ Existing Chart } & \multirow{2}{*}{ 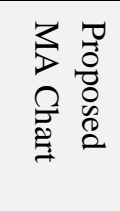 } & \multicolumn{2}{|c|}{ Existing Chart } & \multirow{2}{*}{ 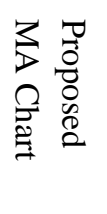 } & \multicolumn{2}{|c|}{ Existing Chart } \\
\hline & & 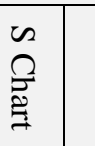 & 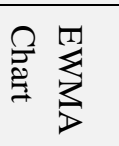 & & $\stackrel{\Omega}{\Omega}$ & 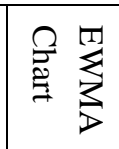 & & 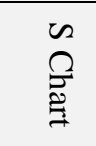 & 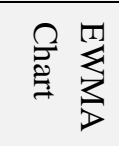 & & $\stackrel{\sim}{2}$ & 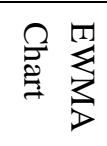 \\
\hline$\delta$ & \multicolumn{12}{|l|}{ ARLs } \\
\hline 1 & 371.75 & 328.8 & 377.19 & 371.76 & 330.49 & 369.8 & 366.21 & 256.9 & 368.29 & 373.15 & 341.8 & 370.75 \\
\hline 0.99 & 278.48 & 258.1 & 305.52 & 276.12 & 233.73 & 276.4 & 299.86 & 143.6 & 296.82 & 269.57 & 202.9 & 278.49 \\
\hline 0.95 & 93.75 & 28.7 & 137.4 & 93.34 & 78.64 & 234.8 & 118.78 & 98.2 & 216.7 & 120.98 & 98.5 & 162.4 \\
\hline 0.92 & 46.26 & 10.1 & 79.27 & 45.89 & 46.23 & 49.5 & 67.35 & 54.7 & 168.33 & 67.37 & 56.5 & 125.5 \\
\hline 0.9 & 30.93 & 18.5 & 62.08 & 29.43 & 25.13 & 89.12 & 45.55 & 31.4 & 55.51 & 47.86 & 40.04 & 54.92 \\
\hline 0.85 & 14.44 & 46.8 & 26.07 & 15.88 & 15.41 & 58.45 & 20.54 & 19.7 & 42.65 & 25.99 & 12.8 & 32.92 \\
\hline 0.8 & 8.35 & 8.7 & 18.24 & 7.65 & 8.47 & 35.6 & 13.51 & 12.5 & 21.56 & 18.21 & 8.67 & 27.2 \\
\hline 0.7 & 5.98 & 4.76 & 9.4 & 5 & 4.37 & 15.8 & 5.92 & 7.8 & 15.93 & 9.77 & 4.32 & 11.76 \\
\hline 0.6 & 5 & 6.34 & 5.83 & 5 & 3.28 & 6.43 & 5.09 & 4.3 & 7.09 & 5.06 & 3.17 & 9.1 \\
\hline 0.5 & 5 & 5.02 & 5.28 & 5 & 3.12 & 6.32 & 5 & 3.1 & 6.87 & 5 & 3.45 & 6.03 \\
\hline
\end{tabular}
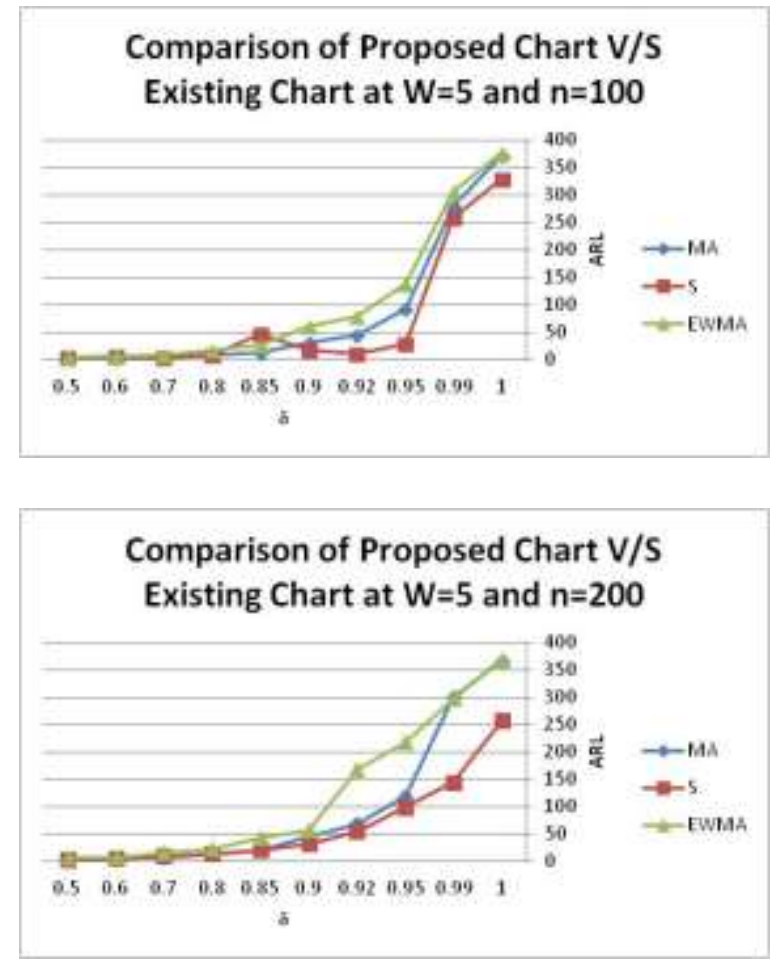
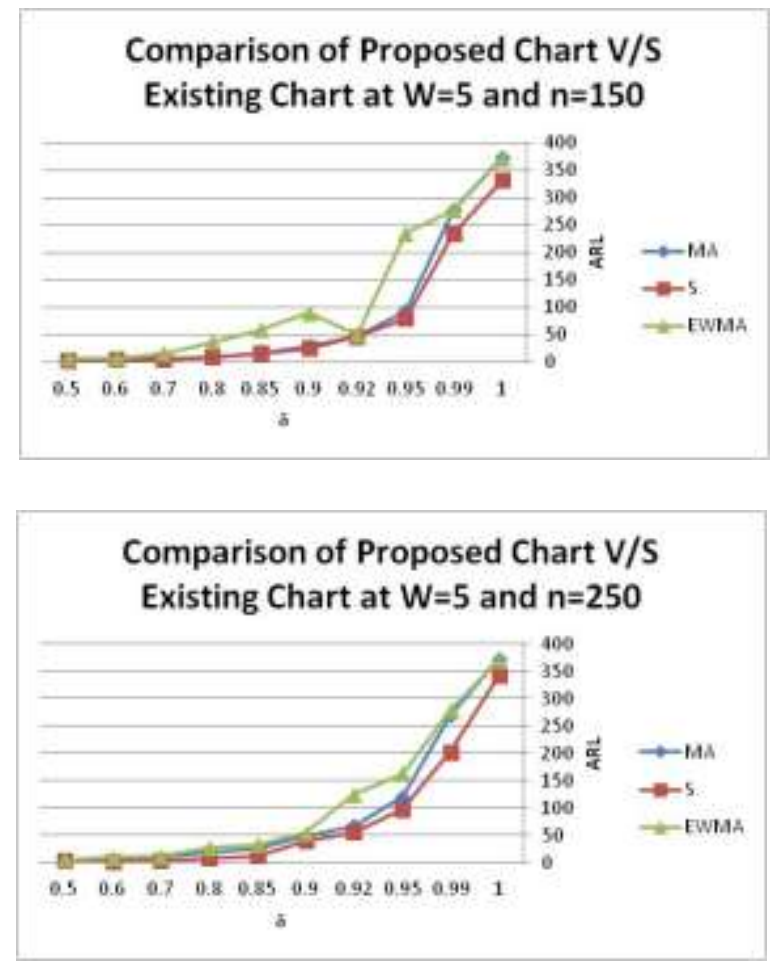

Figure 3:ARL Comparison at $\mathrm{W}=5$ and $n=100,150,200,250$

When $\mathrm{w}=5$ is used for $\mathrm{n}=100,150,200$ then the process is also in control, although there are few points which falls relatively within the limits but they may fall outside the limit due to any cause $w=5$ and $n=250$ there are 26 such points which do not fall within the control limit. 
International Journal of Current Science Research and Review

ISSN: 2581-8341

Volume 03 Issue 10 October 2020

DOI: 10.47191/ijcsrr/V3-i10-02, Impact Factor: 6.595

IJCSRR@ 2020

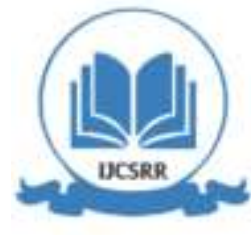

www.ijcsrr.org

Table 3: ARLs when $w=7$

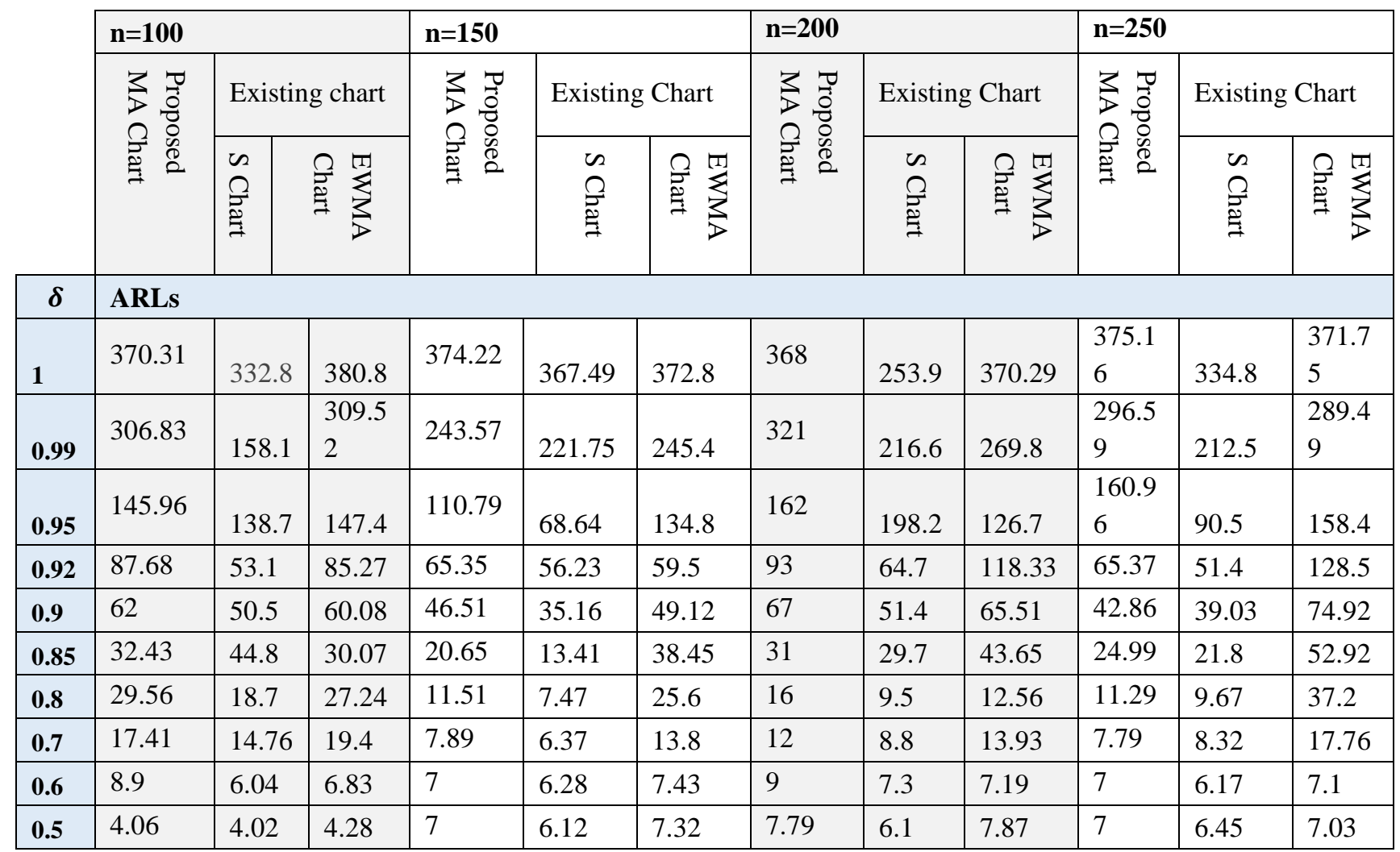

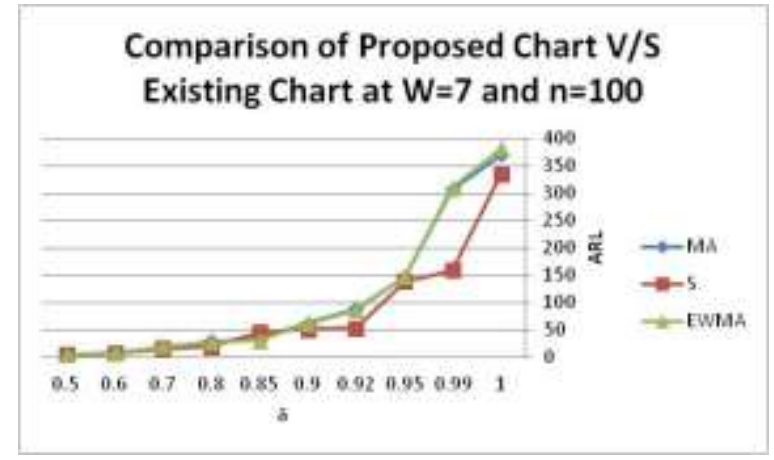

Comparison of Proposed Chart V/S

Existing Chart at $W=7$ and $n=200$

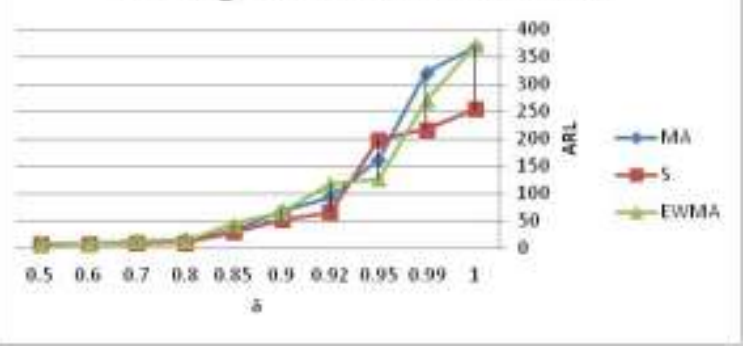

\section{Comparison of Proposed Chart V/S}

Existing Chart at $W=7$ and $n=150$

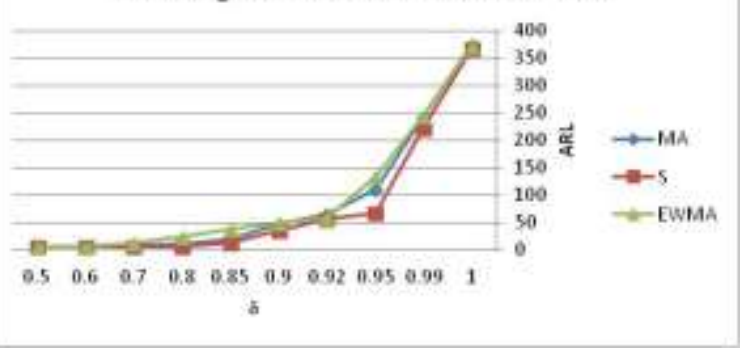

\section{Comparison of Proposed Chart V/S}

Existing Chart at $\mathrm{W}=7$ and $n=250$

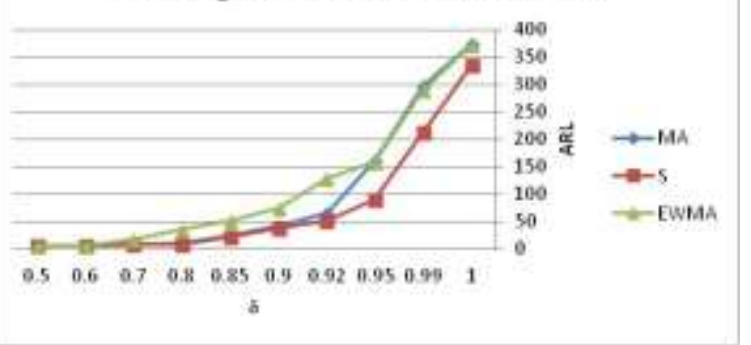

Figure 4: ARL comparison at $\mathrm{W}=7$ and $n=100,150,200,250$ 
International Journal of Current Science Research and Review

ISSN: 2581-8341

Volume 03 Issue 10 October 2020

DOI: 10.47191/ijcsrr/V3-i10-02, Impact Factor: 6.595

IJCSRR@ 2020

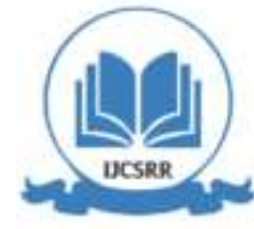

WWW.ijcsrr.org

Under $\mathrm{w}=7$ and $\mathrm{n}=150,1$ issue is found which indicates the process is going out of control where as $\mathrm{w}=7, \mathrm{n}=250$ then 37 such issues found in the process which required some corrective measurements and at $n=100$ the process is in control state.

Table 4: ARLs when $w=9$

\begin{tabular}{|c|c|c|c|c|c|c|c|c|c|c|c|c|}
\hline & \multicolumn{3}{|l|}{$n=100$} & \multicolumn{3}{|l|}{$n=150$} & \multicolumn{3}{|l|}{$\mathrm{n}=\mathbf{2 0 0}$} & \multicolumn{3}{|l|}{$n=250$} \\
\hline & \multirow{2}{*}{ 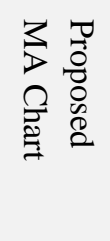 } & \multicolumn{2}{|c|}{ Existing chart } & \multirow{2}{*}{ 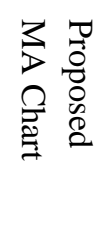 } & \multicolumn{2}{|c|}{ Existing Chart } & \multirow{2}{*}{ 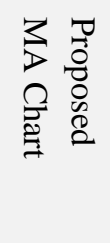 } & \multicolumn{2}{|c|}{ Existing Chart } & \multirow{2}{*}{$\begin{array}{ll}3 & 0 \\
D & 0 \\
0 & 0 \\
2 & 0 \\
0 & 0\end{array}$} & \multicolumn{2}{|c|}{ Existing Chart } \\
\hline & & 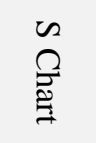 & 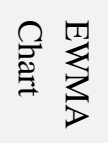 & & 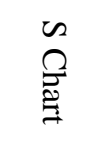 & 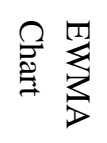 & & 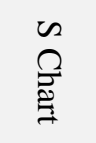 & 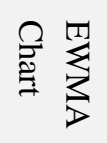 & & 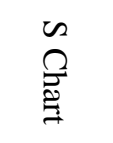 & 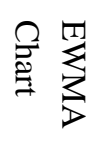 \\
\hline$\delta$ & \multicolumn{12}{|l|}{ ARLs } \\
\hline 1 & 364.25 & 328.8 & 369.4 & 373.75 & 350.49 & 370.49 & 376.43 & 250.9 & 377.29 & 375.16 & 324.8 & 376.75 \\
\hline 0.99 & 274.5 & 145.1 & 299.56 & 270.48 & 215.75 & 275.75 & 307.86 & 236.6 & 369.8 & 266.95 & 232.52 & 279.34 \\
\hline 0.95 & 139.43 & 133.9 & 142.4 & 98.75 & 58.64 & 98.8 & 276.49 & 188.6 & 134.7 & 105.96 & 80.5 & 168.46 \\
\hline 0.92 & 92.74 & 52.1 & 89.28 & 47.26 & 46.23 & 53.5 & 121.31 & 74.7 & 124.33 & 56.37 & 41.4 & 68.58 \\
\hline 0.9 & 45.25 & 43.8 & 54.18 & 33.93 & 36.16 & 40.12 & 79.45 & 47.4 & 85.51 & 46.68 & 32.03 & 54.92 \\
\hline 0.85 & 29.92 & 20.8 & 35.03 & 24.44 & 15.41 & 28.45 & 39.8 & 20.7 & 47.67 & 29.33 & 19.8 & 58.9 \\
\hline 0.8 & 13.2 & 12.7 & 17.24 & 18.35 & 9.47 & 12.6 & 20 & 12.5 & 22.56 & 17.29 & 8.63 & 27.2 \\
\hline 0.7 & 9.67 & 7.76 & 12.43 & 15.98 & 9.37 & 10.8 & 13.76 & 7.8 & 17.93 & 9.34 & 7.32 & 19.68 \\
\hline 0.6 & 7.77 & 5.04 & 7.83 & 5.09 & 4.28 & 9.43 & 9.65 & 6.3 & 9.79 & 9 & 5.07 & 9.19 \\
\hline 0.5 & 7 & 5.02 & 7.28 & 5 & 4.12 & 9.32 & 9 & 5.1 & 9.77 & 9 & 4.15 & 9.03 \\
\hline
\end{tabular}
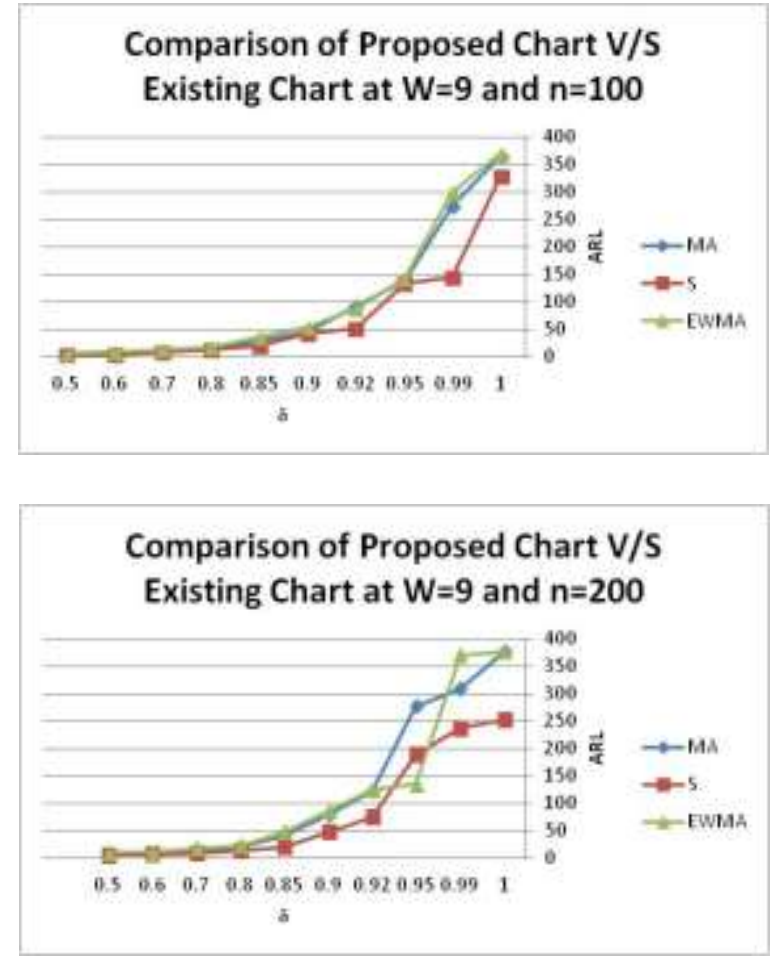
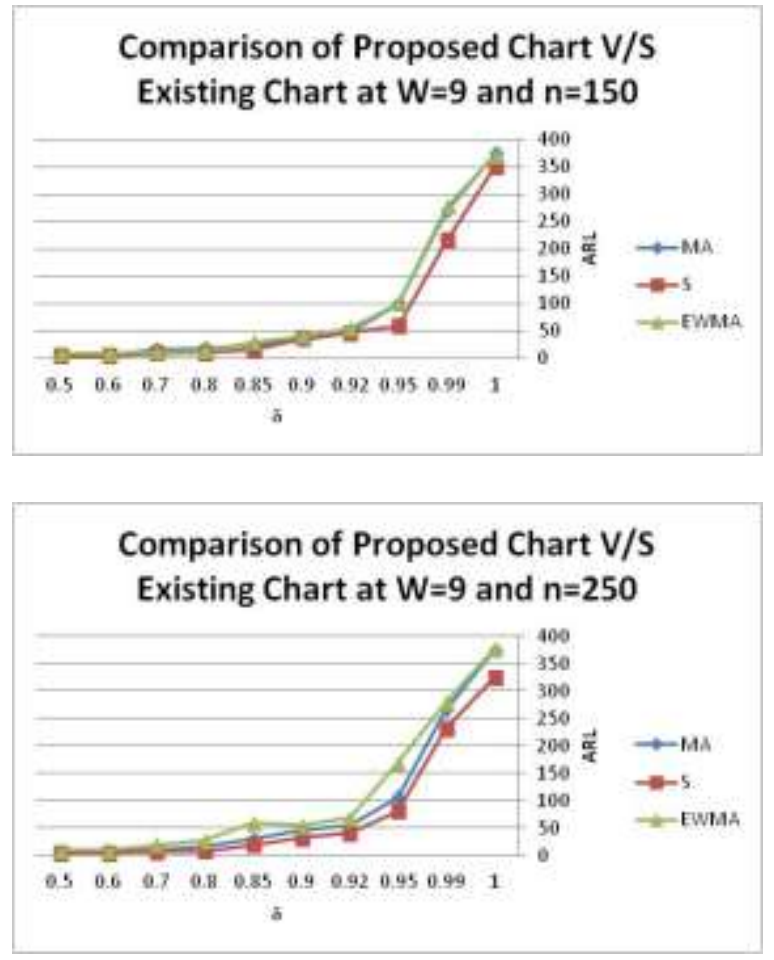

Figure 5: ARL Comparison at $\mathrm{W}=9$ and $\mathrm{n}=100,150,200,250$ 


\section{International Journal of Current Science Research and Review}

ISSN: 2581-8341

Volume 03 Issue 10 October 2020

DOI: 10.47191/ijcsrr/V3-i10-02, Impact Factor: 6.595

IJCSRR@ 2020

WWW.ijcsrr.org

When $n=250$ and $w=9$ there are 53 such points which fall outside the control limit and show that the process is not in control. It means that when we increase the sample size and also increase the different values of $w$, then their limits becomes shorter and points fall outside the control limit.

The aim of this analysis is to analyze the number of failures or faulty products during the manufacturing process and also to examine the impact of using different moving average statistical values in different sample sizes. To evaluate the performance of the proposed chart, it is compared with S chart and the most advanced chart EWMA chart. Average run length is also calculated to check the average number of sample point falls inside the control limits before any false alarm.

In this study we have collected data over an interval of time. The quality characteristic of interest in study is number of flaws in 5 linear yard cloth, which follows Poisson distribution. After the identification of distribution, parameter of the distribution is set this is the mean because the distribution has only one parameter that is mean. Different values of moving average statistic is chosen by using SAS software, which are w=3, 5, 7 and 9. Different sample of sizes used in this study are: 100, 150, 200 and 250.

In this study initially we have to calculate control limits under different MA statistics to check the effect on control limits by using different values of span and sample sizes for this purpose Sigma Magic software is used to calculate the control limits and illustrate by graph to observe that at which points process is going out of control and how many points fall outside the control limits.

\section{CONCLUSION}

This section presents the conclusion of current study. This study is carried out to develop a new MA chart for Poisson distribution. These control charts have been recommended for observing the quantity of failures when the distribution is non-normal. It's been experiential that the proposed control chart is a proficient control chart to detect small shifts during the process.

The main objective of this research is to construct a control chart for normal distribution and to analyze the impact of the use of variable sample size and moving average statistics on the mean distribution parameter. But there are number of instructions left in this study, therefore further research work is carried out on this study using another non-normal distribution, can be used to monitor the location and scale parameter of any distribution and the proposed chart be able to extend by means of different values of " $\mathrm{w}$ " and sample size.

\section{REFERENCES}

1. D. C. Montgomery, "Introduction to statistical quality control," Wiley, 2009.

2. M. Martin, The map and the rope: Finnish nominal inflection as a learning target, University of Jyv, 1995.

3. M. R. R. J. T. P. R. a. W. Z. G. Stoumbos, "The state of statistical process control as we proceed into 21 st century," Journal of American statistical Association, pp. 992 - 998, 2000.

4. H. B. Wong, F. F. Gan, and T.C Chang, "Design of moving average control chart," jounal of statistical computer simulation, pp. 47 - 62, 2004.

5. S.Knoth, "Accurate ARL calculation for EWMA control charts monitoring normal mean and variance simultaneously.," Sequential Anal. Vol. 26, pp. 251-263, 2007.

6. R.S.Sparks, "A group of moving averages control plan for signaling varying shifts," Quality Eng., pp. 519-532, 2003.

7. M. a. P.Yap, "Joint monitoring of process mean and variability with a single moving average control chart," Quality Eng., pp. 51-65, 2007.

8. M. B. K. a. P. Yap, "Joint monitoring of process mean and vaariability with a single moving average control chart," Quality Engeenring, vol, 17, pp. 51 - 65, 2007.

9. L. C. J. a. A. M.Aslam, "A control chart for COMU Poisson distribution using multiple dependent tate sampling," Quality Rel. Eng. Int, pp. 2803-2812, 2016.

10. M. A. a. C. H. J. L. Ahmad, "Designing of X-bar control charts based on process capability index using repetitive sampling," Trans. Ins. Meas. Control, vol 36, pp. 367 - 374, 2013.

11. R. S. Sparks, "A group of moving averages control plan for signaling varying location shifts," Quality Engneering, pp. $519-532,2003$.

12. M. B. K. a. V. Wong, "A double moving average control chart," Communication statistical simulation computer, vol 37, pp. $1696-1708,2008$. 


\section{International Journal of Current Science Research and Review}

ISSN: 2581-8341

Volume 03 Issue 10 October 2020

DOI: 10.47191/ijcsrr/V3-i10-02, Impact Factor: 6.595

IJCSRR@ 2020

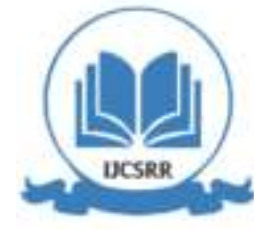

Www.ijcsrr.org

13. G. R. D. M. a. K. S. W. Molanau, "A program for ARL calculation for multivariate EWMA charts," Journal of quality technology, vol 33, p. 515, 2001.

14. S. S. a. Y. A. C. Chananet, "The ARL of EWMA chart for monitoring ZINB model using Markov chain approach," Jounal of applied physics mathematics, p. 236, 2014.

15. M. Aslam, "A mixed EWMAUCUSUM control chart for weibull disttributed quality characteristics," Quality Rel. Eng. Int., vol, 32, pp. 2987 - 2994, 2016.

16. F. A. S. a. H. X. J. C. Fu, "On the average run lenght of quality control schemes using a Markov chain approach," Jounal of statistical probability, pp. 369 - 380, 2002.

17. W. A. Shewhart, "Economic control of quality of manufactured product," American society for quality control, 1931.

18. F. T. C. H.B Wong, "Design of Moving Average Control Chart," J.Statist. Comput. Simul, pp. 47-62, 2004.

19. G. a. G.Masarotto, "An adoptive exponentially weighted moving average control chart," Technometrics, pp. 199-207, 2003.

20. J. C. Benneyan, "Use and interpretation of statistical quality control charts," International Journal for Quality in Health Care, vol. 10, pp. 69-73, 1998. 